\title{
Successful treatment of a severely injured soldier from Afghanistan with pumpless extracorporeal lung assist and neurally adjusted ventilatory support
}

\author{
Thomas Bein • Eric Osborn • Hans Stefan Hofmann • \\ Markus Zimmermann • Alois Philipp • Hans J. Schlitt • \\ Bernhard M. Graf
}

Received: 7 December 2009 /Accepted: 22 April 2010/Published online: 13 July 2010

(C) Springer-Verlag London Ltd 2010

\begin{abstract}
Background Life-threatening acute lung injury due to combat and/or terror attacks is associated with high mortality. The successful management includes the use of "rescue" extracorporeal lung assist and early transport by aeromedical evacuation teams.

Aims Description of the pre-hospital support of a severely injured soldier with a pumpless extracorporeal arteriovenous lung assist in critical hypercapnia/hypoxemia.

Method A British soldier suffered from severe gunshot injuries to the chest and abdomen in Afghanistan. After traumatic pneumonectomy, he developed critical hypercapnia/hypoxemia. He was mechanically ventilated and supported with a pumpless interventional extracorporeal lung assist (iLA, Novalung, Talheim, Germany) and transferred to Germany. Results A sufficient $\mathrm{CO}_{2}$ extraction and improvement in oxygenation enabled the safe transportation and lung protec-
\end{abstract}

T. Bein $(\bowtie) \cdot$ M. Zimmermann $\cdot$ B. M. Graf

Department of Anaesthesia and Critical Care,

University Hospital Regensburg,

93042 Regensburg, Germany

e-mail: thomas.bein@klinik.uni-regensburg.de

H. S. Hofmann · A. Philipp

Department of Heart and Thoracic Surgery,

University Hospital Regensburg,

Regensburg, Germany

H. J. Schlitt

Department of General Surgery,

University Hospital Regensburg,

Regensburg, Germany

E. Osborn

Trauma Surgery/Surgical Critical Care,

Landstuhl Regional Medical Center,

Landstuhl, Germany tive ventilation. Weaning from mechanical ventilation was promoted by the application of a new neurally adjusted ventilatory assist (NAVA). The patient recovered, and he left Germany in stable condition.

Conclusion Novel techniques in extracorporeal lung assist and in ventilatory support may help save lives even in disaster medicine.

Keywords Traumatic lung injury .

Extracorporeal lung assist - Disaster medicine .

Neurally adjusted ventilatory assist

A 19-year-old British soldier sustained gunshot injuries to the chest and abdomen in Afghanistan. He arrived to the emergency room awake, but haemodynamically unstable. He was emergently intubated and transferred to the operating room. Extended exploration revealed right haemopneumothorax, left pneumothorax, grade IV liver injury with disruption of the right lobe, extensive destruction of the right lung and diaphragm injury. After laparotomy, portal triad occlusion was performed, and the haemorrhage was controlled with vessel ligation, abdominal packing and zeolite (QuikClot, Z-Medica, Wallingford, CT). A traumatic pneumonectomy was performed with staples, and the chest and abdomen were packed and temporarily closed after insertion of chest tubes and drains. The patient received 52 units of packed red blood cells and 52 units of fresh frozen plasma.

After the surgery, the haemodynamic situation stabilized, but the patient developed severe hypercapnia $\left(\mathrm{PaCO}_{2}\right.$ $>100 \mathrm{mmHg}$ ) with acidosis (arterial $\mathrm{pH}<7.1$ ) and hypoxemia $\left(\mathrm{PaO}_{2} 66 \mathrm{mmHg}\right.$ with $\mathrm{FIO}_{2}$ 0.8). The medical staff decided to support him with a pumpless extracorporeal arteriovenous interventional lung assist (iLA, Novalung, Talheim, Germany) to enable a transfer to a specialized centre (Regensburg University Hospital) for further treatment, since 
Fig. 1 A severely injured soldier with acute respiratory failure and the pumpless interventional lung assist (iLA)

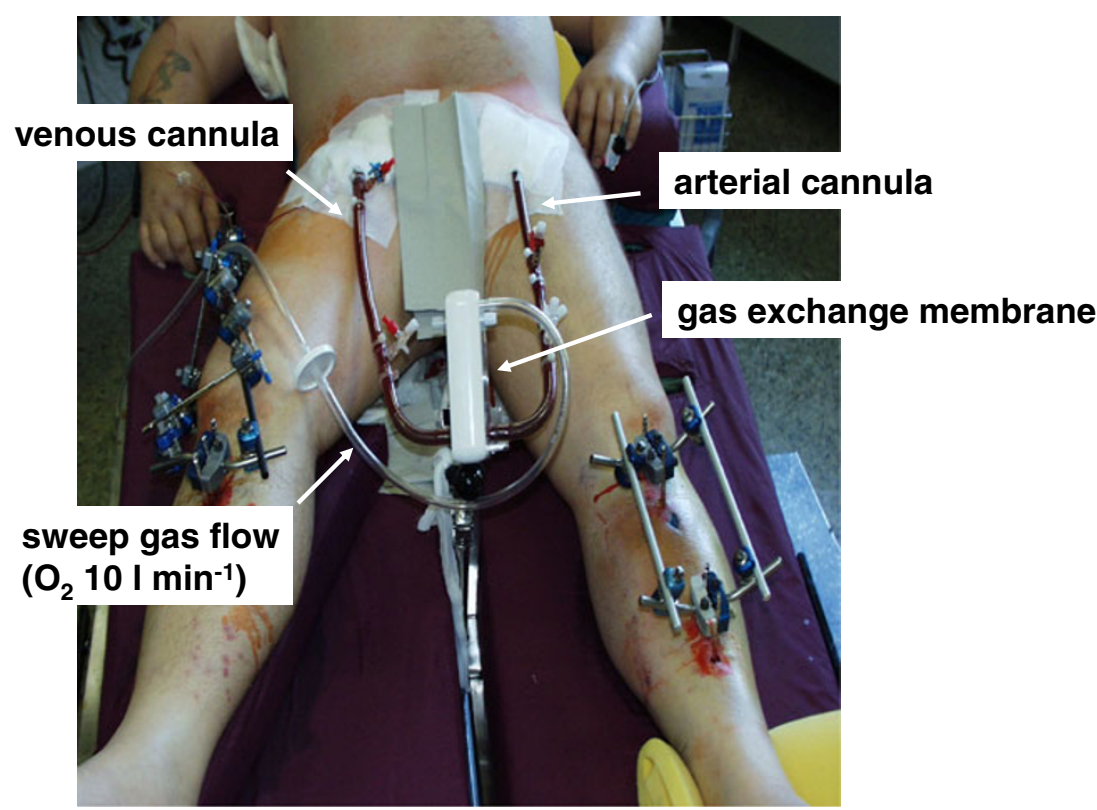

they have special experience in the management of severely injured soldiers from Iraq [1]. In brief, iLA is a single-use ultracompact extrapulmonary gas exchange system perfused by the heart (see the extensive description elsewhere [2]). Apart from an oxygen supply (10-12 $\left.1 \mathrm{~min}^{-1}\right)$, the system does not require additional energy or substrate sources. A passive femo-femoral shunt flow generated by the arterial blood pressure through a lung assist device (iLA NovaLung ${ }^{\circledR}$ $\mathrm{GmbH}$, Talheim, Germany) produces sufficient $\mathrm{CO}_{2}$ extraction and a moderate improvement in arterial oxygenation at a flow rate of approximately $1.0-1.51 \mathrm{~min}^{-1}$. An average driving pressure difference of $60-80 \mathrm{mmHg}$ (femoral arteryfemoral vein) is mandatory. The entire effective gas exchange surface area amounts to $1.3 \mathrm{~m}^{2}$. Integration of a heat exchanger is not necessary as temperature loss due to convection is negligible. iLA is suitable for patients with potentially reversible respiratory failure resulting from, for instance, trauma, aspiration, pancreatitis and sepsis. Contra-

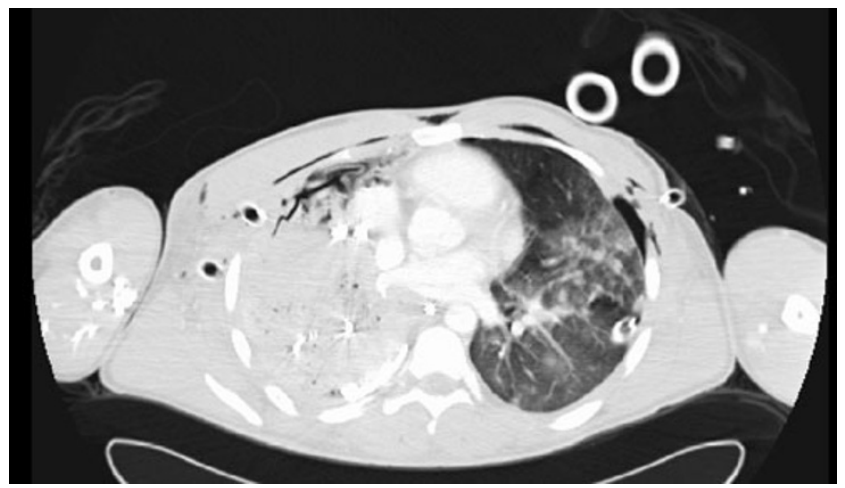

Fig. 2 Chest imaging by computer tomography demonstrating a traumatic right pneumonectomy with packing and injured lung tissue on the left indication for the application of the system is a haemodynamic depression of cardiac origin.

In order to connect the ILA to the patient, a special percutaneous cannulation system was developed fulfilling the following conditions: implantable with the Seldinger technique, cannulae walls extremely thin to optimize low resistance to flow and availability in various diameters (13$17 \mathrm{~F}$ ). In every individual case, the size of the cannula used (arterial: $13-15 \mathrm{~F}$, venous: $17-19 \mathrm{~F}$ ) is determined by the diameter of the vessel to be cannulated. Prior to puncture of the femoral artery, the diameter should be measured by ultrasound sonography. After cannulation of the femoral artery and vein, the system is connected, primed with hydroxyethyl starch $(250 \mathrm{ml})$ and then the circulation is started (Fig. 1). Functional control is achieved through a monitoring device ("Clamp On" Sensor, NovaLung ${ }^{\circledR}$ $\mathrm{GmbH}$, Talheim, Germany) that calculates blood flow through the system by means of ultrasound technology.

The iLA was placed in the field hospital, and the patient was then transported from Afghanistan to Germany by a specialized team trained in the use of iLA.

The patient arrived in critical condition. A CT scan demonstrated the post-pneumonectomy cavity (Fig. 2), patchy contralateral pulmonary consolidation and retained intraabdominal packing. Over the subsequent $48 \mathrm{~h}$, the patient continued to be ventilated in a lung-protective mode (tidal volume $220 \mathrm{ml}$, positive end expiratory pressure $12 \mathrm{~cm} \mathrm{H}_{2} \mathrm{O}$ ) with the result of only moderate hypercapnia $\left(\mathrm{PaCO}_{2} 56 \mathrm{mmHg}\right)$ because of the $\mathrm{CO}_{2}$ removal capacity of the iLA system. Repeat thoracotomy was performed, and the bronchus stump was re-stapled, a biliary duct leak was drained externally, and the patient recovered slowly. 
Over the next days, the patient stabilized with continued iLA, but the mechanical ventilatory support could not be diminished: we observed severe fatigue syndrome of the remaining left diaphragm and a catabolic state. An augmented spontaneous breathing trial resulted in patient-ventilator asynchrony and critical deterioration of the gas exchange. After tracheostomy, we decided to apply a new neurally adjusted ventilatory assist (NAVA, Maquet, Sweden), which delivers pressure in proportion to the electrical activity of the diaphragm, assessed by a special nasogastric tube with electrodes [3]. The patient was successfully weaned within 10 days, and the iLA system was removed. The patient recovered, and he was transferred to a Military Hospital spontaneously breathing in stable condition.

\section{Discussion}

In Iraq and Afghanistan, soldiers are still exposed to combat and/or terror attacks. Successful combat care requires efficient casualty care centers and an early transport of critically injured patients by aeromedical evacuation teams. The use of extracorporeal lung assist by acute lung rescue teams has been reported in soldiers suffering from life-threatening acute lung injury [4]. We believe that our patient would not have survived the transport without early implementation of iLA "in the field". The system provides excellent $\mathrm{CO}_{2}$ elimination, allowing lung protective ventilation of the remaining lung. We believe that the addition of a novel ventilation mode (NAVA), characterized by proportional unloading of the respiratory muscles, improved subject-ventilator synchrony, minimized inspiratory pressures and enabled successful weaning in a critical limitation of breathing capacity without perspective of early lung transplantation. We conclude that novel techniques in ventilatory support save lives even in disaster medicine.

\section{Contributions}

All authors were involved in managing the patient, discussing and planning logistic aspects of transportation and writing the report.

\section{References}

1. Zimmermann M, Philipp A, Schmid FX et al (2007) From Baghdad to Germany: use of a new pumpless extracorporeal lung assist system in two severely injured US soldiers. ASAIO J 53:e4-e6

2. Bein T, Weber F, Philipp A et al (2006) A new pumpless extracorporeal lung assist in critical hypoxemia/hypercapnia. Crit Care Med 34:1372-1377

3. Brander L, Leong-Poi H, Beck J et al (2009) Titration and implementation of neurally adjusted ventilatory assist in critically ill patients. Chest 135:695-703

4. Dorlac G, Fang R, Pruitt V et al (2009) Air transport of patients with severe lung injury: development and utilization of the Acute Lung Rescue Team. J Trauma 66:S164-S171

Prof. Dr. Thomas Bein is the Attending Director of Intensive Care at the University Hospital in Regensburg, Germany. He has earned the European Diploma in Intensive Care Medicine and belongs to numerous societies focusing on anesthesiology and intensive care medicine. He was a member of the Standing Committee on Organ Donation of the German Medical Association. His scientific interests include extracorporeal lung assistance in severe respiratory failure, positioning therapy for acute lung injury, and psychological aspects of organ donation. 